\title{
Malignant myoepithelioma (myoepithelial carcinoma) of the breast: a detailed cytokeratin study
}

\author{
S R Lakhani, M J O’Hare, P Monaghan, J Winehouse, J-C Gazet, J P Sloane
}

\begin{abstract}
Aims-To study the expression of a range of cytokeratins by malignant myoepithelioma of the breast.

Methods-Immunophenotyping was carried out using a panel of antibodies on paraffin wax embedded and frozen material using immunohistochemistry and double-labelled immunofluorescence. Electron microscopy was also performed. Results-The tumour cells were positive for CAM 5.2, actin, vimentin, and cytokeratin 14 and negative for cytokeratins 18 and 19. Electron microscopy showed well formed desmosomes and hemidesmosomes together with pinocytic vesicles, plentiful rough endoplasmic reticulum and $6 \mathrm{nM}$ microfilaments with focal densities.

Conclusions-The pattern of cytokeratin expression provides further evidence that tumours with a specific myoepithelial phenotype occur rarely in the breast. (f Clin Pathol 1995;48:164-167)
\end{abstract}

Keywords: Malignant myoepithelioma, cytokeratin, breast.

Most breast neoplasms have epithelial cell characteristics but a few are composed partly or purely of cells exhibiting myoepithelial differentiation. ${ }^{1}$ Tavassoli ${ }^{2}$ recognised three main types of myoepithelial proliferations in the breast: (i) myoepitheliosis, (ii) adenomyoepithelioma with a potential for local recurrence but not metastasis, and (iii) myoepithelial carcinoma. Most of the cases, as in other series, were classified as adenomyoepitheliomas, which are generally of low grade malignancy. Myoepithelial carcinomas, however, usually give rise to metastases, ${ }^{34}$ although one purely intraductal case has been described. ${ }^{5}$ These lesions are extremely rare spindle cell tumours requiring a combination of morphology, electron microscopy and/or immunohistological investigations to distinguish them from sarcomas and spindle cell carcinomas. The antibodies most commonly used are CAM 5.2, epithelial membrane antigen (EMA), smooth muscle actin, $\mathrm{S} 100$ protein, and glial fibrillary acidic protein (GFAP). These antibodies are not specific for myoepithelial cells but in combination, positive findings indicate myoepithelial differentiation with a reasonable degree of confidence.

At least 20 different keratins have been distinguished in human epithelia, ${ }^{6}$ with different combinations in different cell types. The myoepithelial cells of the breast express keratins 5, 14, and 17 and the luminal cells keratins 7,8 , 18 , and $19 .{ }^{78}$ Although staining for keratins 14 and 17 has been observed in normal luminal cells and some carcinomas, ${ }^{8}$ it is generally focal and weak compared with the uniform staining observed in myoepithelial cells. The difficulty with detailed keratin phenotyping is the requirement for fresh tissue as many of the antibodies do not bind to formalin fixed, paraffin wax embedded sections. In this study we have undertaken immunophenotyping with a panel
Department of
Histopathology, The Royal Marsden Hospital,

Down's Road, Sutton, Surrey SM2 5PT S R Lakhani J P Sloane

Department of Surgery

$J$ Winehouse

J-C Gazet

Institute of Cancer Research

M J O'Hare

P Monaghan

Correspondence to: Dr S R Lakhani.

Accepted for publication 1 July 1994
Antibodies used and reactivity with tumour samples

\begin{tabular}{|c|c|c|c|}
\hline Antibodies & Source & Antigen & Reactivity with tumour* \\
\hline $\begin{array}{l}\text { Immunohistochemistry** } \\
\text { CAM 5·2 } \\
\text { ICR-2 } \\
\text { Anti-smooth muscle actin (1A4) } \\
\text { Anti-vimentin (MV1) } \\
\text { Anti-S100 } \\
\text { Anti-desmin }\end{array}$ & $\begin{array}{l}\text { Becton-Dickinson } \\
\text { Dr C Dean, ICR } \\
\text { Sigma } \\
\text { Dako } \\
\text { Dako } \\
\text { EuroDiagnostics }\end{array}$ & $\begin{array}{l}\text { CK8,18,19 } \\
\text { Epithelial membrane antigen } \\
\alpha \text {-Actin } \\
\text { Vimentin } \\
\text { S100 protein } \\
\text { Desmin }\end{array}$ & $\begin{array}{l}++ \\
+ \\
+++ \\
+++ \\
+ \\
-\end{array}$ \\
\hline $\begin{array}{l}\text { Double immunofluorescencef } \\
\text { Vimentin/LP34 } \\
\text { LE61/LL002 } \\
\text { LP2K/RCK107 } \\
\text { LL002/RCK107 } \\
\text { 1A4/LL002 } \\
\text { LL002/MV1 } \\
\text { MV1/1A4 } \\
\text { RCK105/IC7 }\end{array}$ & $\begin{array}{l}\text { Labsystems/EBL } \\
\text { EBL/EBL } \\
\text { EBL/FR } \\
\text { EBL/FR } \\
\text { Sigma/EBL } \\
\text { EBL/Dako } \\
\text { Dako/Sigma } \\
\text { FR/FR }\end{array}$ & $\begin{array}{l}\text { Vimentin/CK5,8,18 } \\
\text { CK18/CK14 } \\
\text { CK19/CK14 } \\
\text { CK14/CK14 } \\
\alpha \text {-Actin/CK14 } \\
\text { CK14/Vimentin } \\
\text { Vimentin/ } \alpha \text {-actin } \\
\text { CK7/CK13 }\end{array}$ & $\begin{array}{l}+++1++ \\
-1++ \\
-1++ \\
++1++ \\
+++1++ \\
++1+++ \\
+++1+++ \\
-1-\end{array}$ \\
\hline
\end{tabular}

Key to scoring system:,$+++>75 \%$ tumour cells positive;,$++ 25-75 \%$ tumour cells positive;,$+<25 \%$ tumour cells positive; - , all tumour cells negative.

* In all combinations where there was positivity for both antigens, which reflected extensive co-expression by the tumour cells and not separate cell populations (see fig 2)

a* Undertaken on formalin fixed, paraffin wax embedded sections.

tUndertaken on acetone fixed, frozen sections; in all combinations the primary antibodies were of different IgG subclasses, t Undertaken on acetone fixed, frozen sections; in all combinations the primary antibodies were of
permitting specific visualisation by subclass specific RITC or FITC conjugated secondary antibodies.

permitting specific visualisation by

Source: Becton-Dickinson, Oxford, UK; Sigma, Poole, Dorset, UK; EuroDiagnostics, Stratton, Bude, Cornwall, UK; Labsystems, Source: Becton-Dickinson, Oxford, UK; Sigma, 


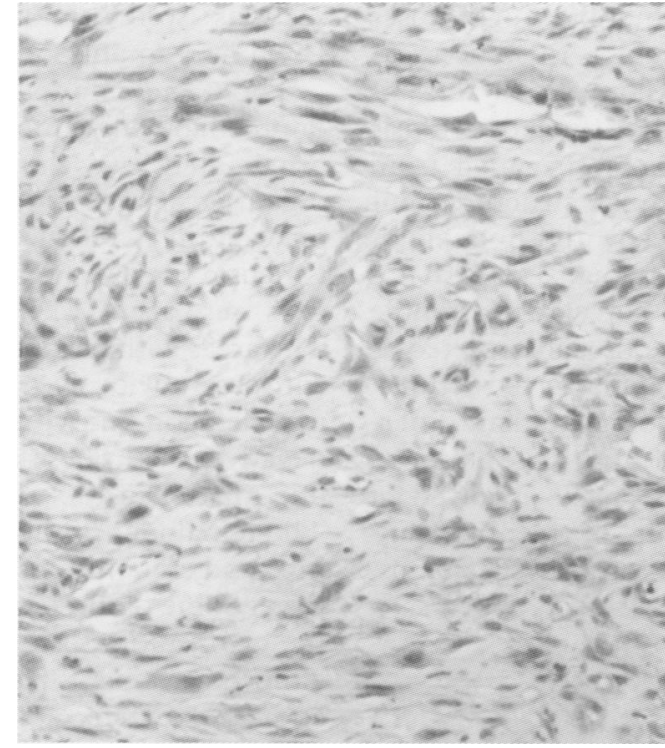

Figure 1 Low power view of a haematoxylin and eosin stained section of the lesion from the axilla showing a spindle cell tumour with only mild pleomorphism and occasional mitotic figures.
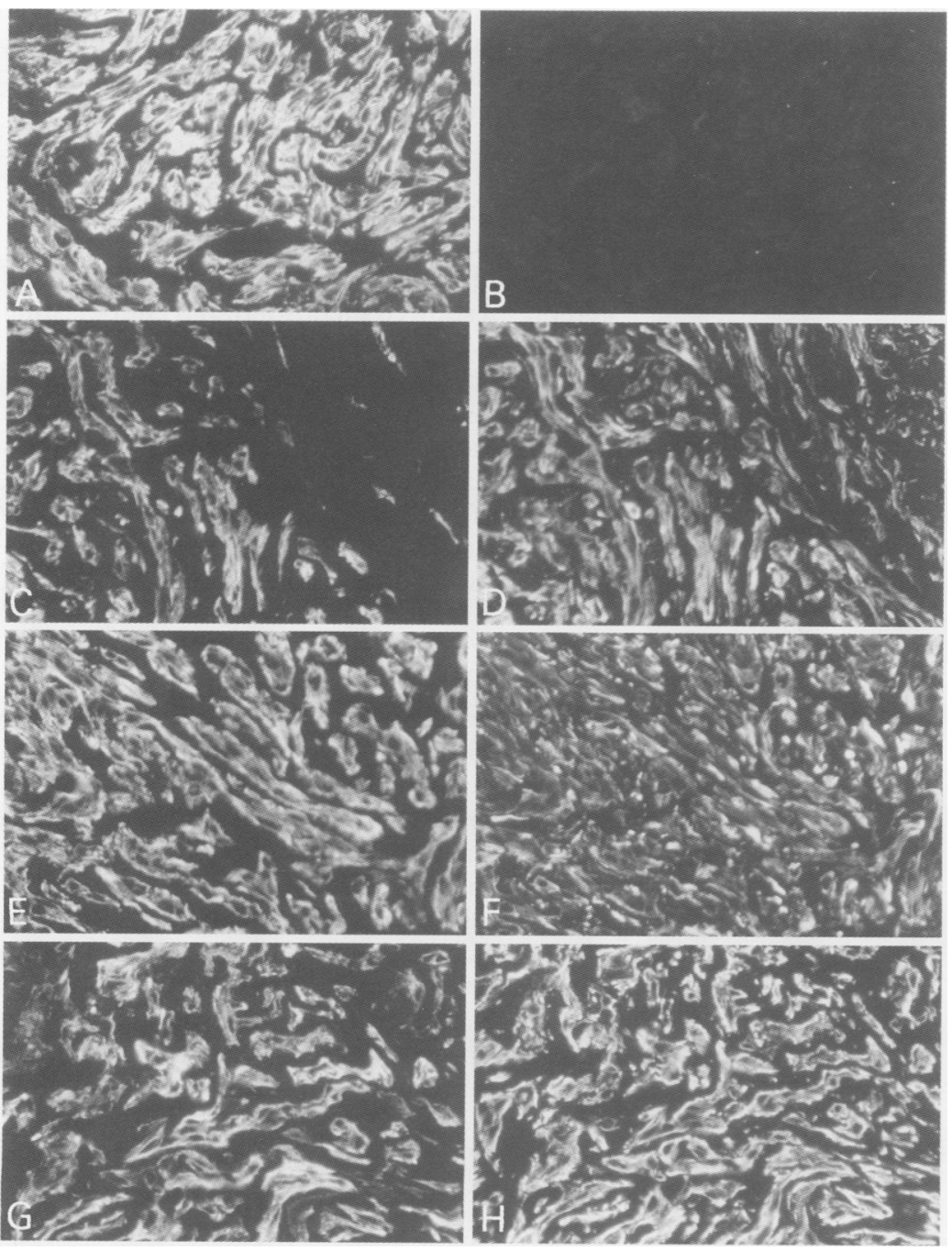

Figure 2 Double indirect immunofluorescence staining of tumour frozen sections showing antigens visualised with RITC on the left and FITC on the right in the same field. $A$ and $B$ show staining for $C K 14$ and $C K 18$, respectively; $C$ and $D C K 14$ together with smooth muscle actin; $E$ and $F C K 14$ and vimentin; and $G$ and $H$ smooth muscle actin and vimentin staining. Tumour fascicles staining for CK14 (but not CK18), smooth muscle actin and vimentin can be seen, interspersed with cytokeratin negative/vimentin positive cells $(F$ and $G$ ) that probably represent normal stromal cells (original magnification $\times 270)$. of monospecific and polyspecific antikeratin antibodies to determine whether a tumour diagnosed as myoepithelial carcinoma by morphology, immunohistology, and electron microscopy exhibited a keratin profile consistent with myoepithelial differentiation.

\section{Methods}

CLINICAL DATA

In April 1987 a 67 year old woman presented with a mass located in the upper outer quadrant of the right breast. Wide local excision and level I axillary dissection were performed. She presented again in June 1991 with another mass in the lower inner quadrant of the same breast. Macroscopic examination showed a cyst-like structure with a smooth grey lining. Staging investigations were again negative and a wide local excision was carried out. In March 1993 a mass in the ipsilateral axilla was excised. A limited skeletal survey at this time revealed metastatic disease in the skull, ribs, lumbar spine, and sternum. She received tamoxifen (20 mg mane) but with no discernible clinical effect. She developed hypercalcaemia and died in June 1993.

At necropsy, there was residual tumour in the right breast and metastases in the left breast, lymph nodes, bones, myocardium, pericardium, kidneys, adrenal glands, liver, spleen, and lungs.

Immunohistochemistry was carried out on paraffin wax embedded tissue from all three surgical specimens using the alkaline phosphatase-antialkaline phosphatase method with Fast Red TR as the substrate. The antibodies used were as shown in the table. Frozen tissue was available only from the mass in the axilla; acetone fixed frozen sections from this specimen were stained with a combination of monospecific (except LP34) antikeratin monoclonal antibodies and visualised using narrow-band pass green and red filters and subclass specific second antibody fluorochrome (RITC and FITC) conjugates (Southern Biotechnology via Europath, Bude, UK).

For ultrastructural analysis, formalin fixed tissue obtained from the axillary mass was used. It was post-fixed in $1 \%(\mathrm{w} / \mathrm{v})$ osmium tetroxide in $0.1 \mathrm{M}$ phosphate buffer for two hours, dehydrated in ethanol and embedded in Epon/ Araldite. Representative areas of the tumour were selected from toluidine blue stained $1 \mu \mathrm{m}$ sections. Ultrathin sections were cut with a diamond knife on a Leica (Milton Keynes, UK) OMU4 ultramicrotome, collected on copper grids, contrasted with uranyl acetate and lead citrate (Leica Ultrostainer), and viewed in a Philips CM10 at $80 \mathrm{Kv}$.

\section{Results}

HISTOLOGICAL FINDINGS

All surgical specimens, two from the breast and one from the axilla, showed similar features. The mass from the axilla consisted of metastatic deposits in lymph nodes. The tumour was composed of uniform spindle cells with only a mild degree of nuclear pleomorphism (fig 1) 
and exhibited moderate numbers of mitoses (five per 10 high power fields). In some areas the cells were plump and epithelioid, and appeared to line cleft-like spaces. Foci of necrosis were also seen. The original specimen from 1987 showed some glandular structures but they were present only focally, did not exhibit cytological or structural atypia, and did not show any evidence of transition with the spindle cell component. They were thus interpreted as entrapped rather than neoplastic structures. There was no evidence of glandular differentiation or in situ tumour in any of the specimens. Sections of all the organs involved at necropsy revealed tumour of identical appearance to that seen in the surgical specimens.

\section{IMMUNOHISTOCHEMISTRY/ IMMUNOFLUORESCENCE}

Immunohistology using conventional markers showed that the tumour cells were CAM 5.2, actin and vimentin positive. The immunohistochemical profile of the tumour is presented in the table. Staining with a polyspecific anticytokeratin antibody (LP34) showed that at least $75 \%$ of the cells in the lesion were keratin positive. All the cells that were keratin positive were also vimentin positive when frozen tumour
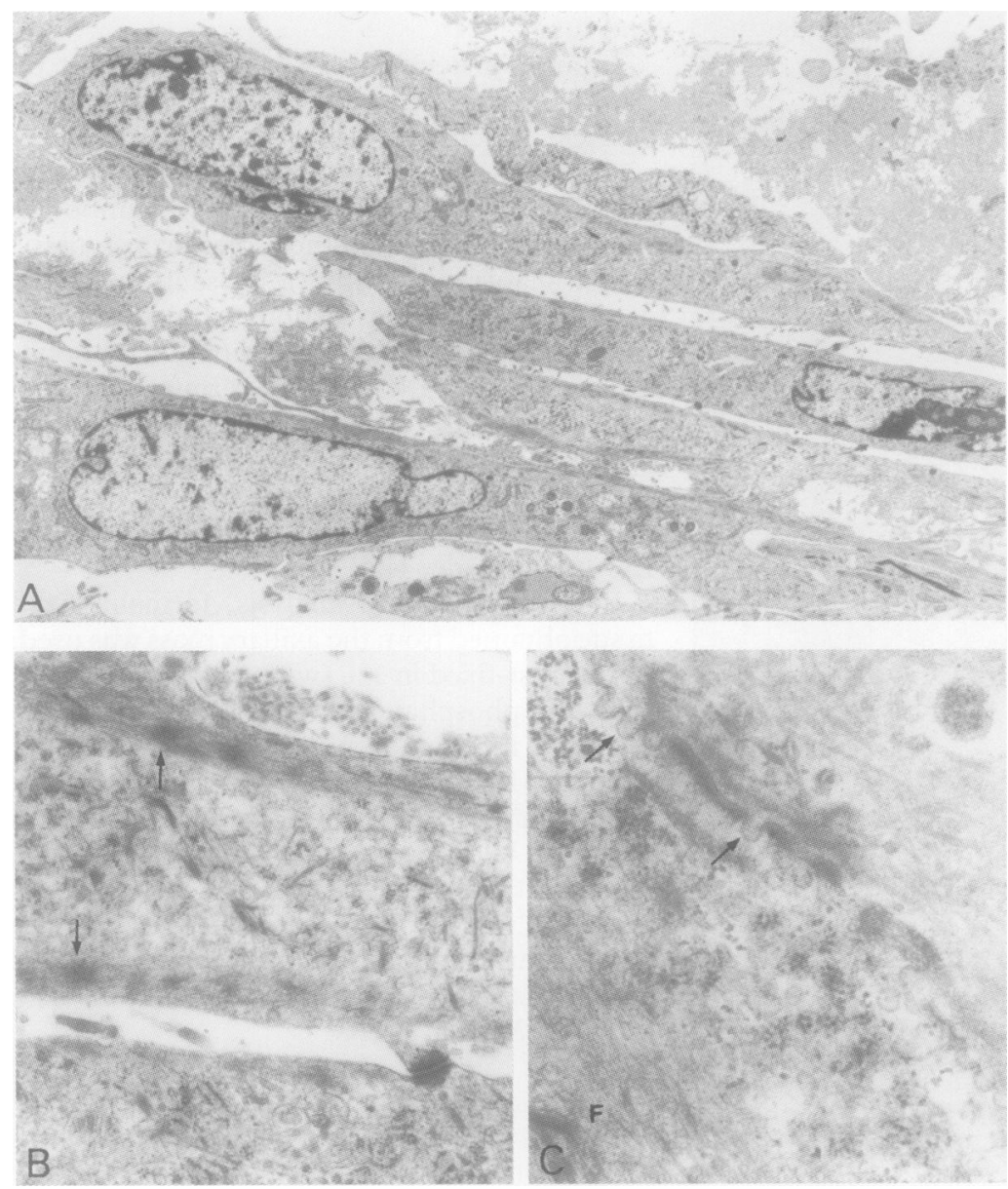

Figure 3 A: Low power electron micrograph of spindle shaped tumour cells (original magnification $\times 5200)$. B: Electron micrograph showing two tumour cells with peripheral areas of myofilaments with focal densities (arrows). The tumour cells are joined by a desmosome. Keratin filaments are present in the cell cytoplasm (original magnification $\times 19600)$. C: High power electron micrograph of the membrane of a tumour cell showing hemidesmosomes and numerous pinocytotic vesicles (arrows). The cell cytoplasm also contains myofilaments $(F)$ (original magnification $\times 48000)$ sections were simultaneously stained with LP34 and an antibody to vimentin.

Three staining patterns were seen using double-labelling immunofluorescence: (i) approximately two thirds of the tumour cells, organised largely in discrete fascicles, were cytokeratin (CK) 14, smooth muscle actin and vimentin positive (figs $2 \mathrm{~A}, 2 \mathrm{D}$, and $2 \mathrm{~F}$ ). These cells were also CK18 and CK19 negative. (ii) The areas with pattern A merged at their edges with less obviously fascicular areas of smooth muscle actin and vimentin positive but CK14 negative cells. These cells accounted for about one quarter of the tumour cells (fig $2 \mathrm{C}$ ). (iii) The remainder of the cells were vimentin positive and smooth muscle actin and CK14 negative. Some of these were interspersed between the cytokeratin positive cell bundles and were almost certainly stromal fibroblasts (figs $2 \mathrm{E}$ and $2 \mathrm{~F}$ ). Others appeared to be contiguous with cells showing pattern $B$ and could have been either fibroblasts or tumour cells that had lost both actin and CK14 expression. They represented the least numerically significant component. Hence, over half the cells in this metastatic lesion showed a specific myoepithelial phenotype with concurrent CK14, smooth muscle actin and vimentin positive staining and CK18 and CK19 negative staining in the same cells.

\section{ELECTRON MICROSCOPY}

The tumour cells were spindle shaped (fig 3A) and joined by well formed desmosomes. The cytoplasm showed plentiful rough endoplasmic reticulum and zones of $6 \mathrm{nM}$ microfilaments with focal densities near the plasma membrane. Keratin filaments were present in many cells (fig 3B). Basement membrane-like material was associated with occasional tumour cells which exhibited focal membrane thickening and occasional hemidesmosomes, sometimes in association with pinocytotic vesicles (fig $3 \mathrm{C}$ ).

\section{Discussion}

Myoepithelial carcinomas are difficult to diagnose. Unlike adenomyoepitheliomas which exhibit distinctive combined patterns of epithelial and myoepithelial differentiation, they are composed purely of spindle cells and consequently virtually impossible to differentiate from spindle cell carcinomas and sarcomas on morphological examination. It is essential to be able to recognise myoepithelial carcinomas in order to learn more about their natural history and response to treatment. It was interesting to note that tamoxifen had no effect on the tumour in this patient.

To date, immunohistochemistry has been limited to antibodies against smooth muscle actin, S100 protein and GFAP. However, none of these markers on their own are entirely specific for myoepithelial cells or tumours derived from them. Actin may be expressed on tumours exhibiting myofibroblastic or smooth muscle differentiation, and GFAP and S100 on tumours of nerve sheath origin. Combined staining with these antibodies and epithelial 
markers, however, provides adequate evidence of myoepithelial differentiation for routine diagnostic purposes. Electron microscopy may provide further evidence of myoepithelial differentiation.

Detailed keratin profiles have not previously been reported presumably because of the need for frozen material, the infrequency with which the relevant antibodies are used in routine diagnostic practice and the complexity of the staining procedures. In the present case half of the tumour cells in the lesion showed a very specific myoepithelial phenotype-that is, coexpression of CK14, smooth muscle actin and vimentin in the same cells, which were negative for CK7, 13,18 , and 19. These findings provide further definitive evidence of the truly myoepithelial nature of a small proportion of malignant tumours in the breast.
We are grateful to Professors E B Lane and F Ramaekers for the gift of anticytokeratin antibodies.

1 Erlandson RA, Rosen PP. Infiltrating myoepithelioma of the breast. Am $\mathcal{f}$ Surg Pathol 1982;6:785-93.

2 Tavassoli FA. Myoepithelial lesions of the breast. Myoepitheliosis, adenomyoepithelioma, and myoepithelial carcinoma. Am f Surg Pathol 1991;15:554-68.

3 Schurch W, Potvin C, Seemayer TA. Malignant myoepithelioma (myoepithelial carcinoma) of breast: an ultrastructural and immunohistochemical study. Ultrastruct Pathol 1985;8:1-11.

4 Thorner PS, Kahn HJ, Baumal R, Lee K, Moffat W. Malignant myoepithelioma of the breast. An immunohistochemical study by light and electronmicroscopy. Cancer 1986;57:745-50.

5 Tamai $M$. Intraductal growth of malignant mammary myoepithelioma. Am $\mathcal{f}$ Surg Pathol 1992;16:1116-25.

6 Moll R, Franke WW, Schiller DL. The catalog of human cytokeratins: pattern of expression in normal epithelia, tumours and cultured cells. Cell 1982;31:11-24.

7 Taylor-Papadimitriou J, Lane EB. Keratin expression in the mammary gland. In: Neville MC, Daniel CW, eds. The mammary gland. New York: Plenum Press, 1987:181-215.

mammary gland. New York: Plenum Press, 1987:181-215.
8 Wetzels RH, Kuijpers HJH, Lane BE, Leigh IM, Troyanovsky Wetzels RH, Kuijpers $\mathrm{HJH}$, Lane BE, Leigh IM, Troyanovsky
$\mathrm{SM}$, Holland $\mathrm{R}$, et al. Basal cell-specific and hyperproliferation-related keratins in human breast cancer. $\mathrm{Am}$ f Pathol 1991;138:751-63. 